\title{
TOLERÂNCIA ÀS METILXANTINAS E INTERAÇÕES COM O SISTEMA DOPAMINÉRGICO: POSSÍVEIS IMPLICAÇÕES CLÍNICAS
}

\author{
José Eduardo Tanus dos Santos e João Batista T. Rocha \\ Departamento de Química - Centro de Ciências Naturais e Exatas. \\ UFSM - Santa Maria, RS.
}

\section{RESUMO}

Trabalhos recentes sugerem que as metilxantinas poderiam interferir com a eficiência terapêutica dos neurolépticos, uma vez que a catalepsia induzida por haloperidol ou clorpromazina é revertida por metilxantinas. Todavia, estes trabalhos foram feitos através da administração aguda das drogas, o que exclui o possivel desenvolvimento de tolerância às metilxantinas. No presente trabalho fez-se uma revisão da literatura e observou-se que os estudos sobre o desenvolvimento de tolerância às metilxantinas são poucos e, em alguns casos, controversos. Além disto, em nosso laboratório não encontramos tolerância à caféna no tocante à estimulação da atividade locomotora e à reversão de catalepsia induzida por clorpromazina. Estes resultados demonstram a necessidade da execução de estudos clinicos bem controlados com pacientes psiquiátricos que usem drogas de ambos os grupos para determinar se as metilxantinas interferem efetivamente com a eficácia antipsicótica dos neurolépticos.

\section{SUMMARY}

SANTOS, J. E. T. dos and ROCHA, J. B. T. TOLERANCE TO METHYLXANTHINES AND INTERACTION WITH DOPAMINERGIC SYETEM: CLINICAL IMPLICATIONS.

Recent studies have suggested that methylxanthines could change neuroleptics efficiency, since haloperidol or chlorpromazine-induced catalepsy is reversed by methylxanthines. However, these studies were made with acute administration of the drugs, disregarding the possible development of tolerance to methylxanthines. In the present mini-review of the literature it was 
observed that few studies investigated the tolerance to methylxanthines, furthermore there is some controversy between them. In our laboratory we found no tolerance to caffeine in relation to the effect on the rat locomotor activity and its ability in reversing chlorpromazine-induced catalepsy. These results suggest that well-controled clinical studies with psychiatric patients in current use of both kinds of drugs are necessary to establish if methylxanthines actually change neuroleptics antipsychotic efficacy.

\section{INTRODUÇÃO}

\section{MECANISMOS DE AÇ̃̃o DAS METILXANTINAS}

As metilxantinas (cafeina, teofilina e teobromina) são drogas de uso amplo na sociedade ocidental, contudo muitos de seus aspectos farmacológicos e farmacodinâmicos permanecem desconhecidos. Diferentes mecanismos de ação foram propostos, tendo sido invalidados alguns deles atualmente. Sabe-se que a cafeina aumenta a secreção gástrica, a contratilidade miocárdica e melhora a função respiratória. Além disto, a cafeina aumenta a excitabilidade do sistema nervoso central ao nivel de córtex e medula, provavelmente por ativar a formação reticular. Ao nivel comportamental isto pode se traduzir no aumento da atividade motora $(14,27) \mathrm{e}$, em termos de comportamento humano, tem sido sugerido que a cafeina melhore o desempenho intelectual por produzir um fluxo mais intenso do pensamento (incluindo uma melhor associação de idéias), diminuir o cansaço e a fadiga, melhorar a apreciação dos estimulos sensoriais e reduzir o tempo de reação $(15,25)$. Tem sido demonstrado também que a cafeina pode produzir manifestações subjetivas de euforia (19) e ansiedade $(4,5)$. Muitas controvérsias existem na literatura sobre efeitos (11) e muitas são as dificuldades nos estudos clínicos, já que a distinção entre usuários crônicos e não usuários é, em geral, algo confusa.

Loke (25) demonstrou que o uso crônico da droga parece melhorar as funções cognitivas, pois melhorou o desempenho em testes envolvendo cálculos aritméticos e atenção, simultaneamente. A memória a curto prazo não foi afetada, porém a de longo prazo foi melhorada pela droga. Houve um efeito dose dependente, com aumento da ansiedade, tensão emocional, inquietude e diminuição da calma e fadiga. Por outro lado, Henry e Stephens (20) demonstraram que a cafeina aumentava a mortalidade de ratos machos numa situação de estresse social e sugeriram que a cafeína aumentaria o risco do desenvolvimento de estresse social em mamíferos. 
Durante muito tempo se atribuiu os efeitos fisiológicos das metilxantinas à inibição da enzima fosfodiesterase (7). Sabe-se hoje que as concentrações requeridas para que tal inibição ocorra não são atingidas no cérebro, com doses comportamentalmente efetivas (29). Snyder et al (29) demonstraram o envolvimento dos receptores da adenosina nos efeitos comportamentais das metilxantinas, já que o bloqueio dos receptores do tipo Al da adenosina pelas metilxantinas se correlacionava com 0 efeito estimulatório sobre a atividade locomotora. Estes autores demonstraram também que, além de aumentar a atividade motora, as metilxantinas reverteram a inibição desta atividade induzida por um potente agonista dos receptores da adenosina, o L-fenilisopropil-adenosina ou L-PIA (24). Diversas outras evidências têm apontado a participação da adenosina e de seus receptores na regulação da atividade motora, incluindo o uso de inibidores da recaptação e substâncias liberadoras do neurotransmissor (10).

Alguns estudos sugerem que a cafeina pode interagir com diversos sistemas de neurotransmissores, além do sistema purinérgico já mencionado. White et al. (34) investigaram possiveis interações com os sistemas catecolaminérgico e serotoninérgico, valendo-se de tratamentos de ratos com inibidores das vias biossintéticas destes dois sistemas. Observaram que a cafeina produziu efeitos estimulatórios maiores sobre a atividade motora, em comparação com ratos dos grupos de controle, quando os ratos foram tratados com um inibidor da sintese de serotonina; o contrário foi observado quando da utilização de um inibidor da via catecolaminérgica, com diminuição dos efeitos da cafeina. Sugerem então que a sintese de catecolaminas é necessária para que a cafeina exerça seus efeitos. Por outro lado, sugerem que apenas parte dos efeitos da cafeina se devam a mecanismos serotoninérgicos.

\section{TOLERÂNCIA A METILXANTINAS EM MODELOS ANIMAIS E HUMANOS}

Um dos aspectos de grande importância na prática médica que pode estar associado ao uso das metilxantinas diz respeito ao desenvolvimento da tolerância a estes compostos. Diversos estudos têm sido realizados para tentar elucidar esta questão. O texto que segue descreve detalhadamente alguns dos principais estudos com intuito de sugerir que o desenvolvimento e detecção da tolerância podem ser prejudicados pela rapidez com que se desenvolve e regride (14). Todavia, tal sugestão deve ser vista com cuidado, uma vez que está baseada em poucos dados experimentais e utiliza modelos animais.

Chou et al (8) demonstraram o desenvolvimento de tolerância à cafeina em ratos após 14 dias de tratamento crônico, com doses diárias de 5 e $10 \mathrm{mg} / \mathrm{Kg}$ administradas por via 
oral.Considerando que a injeção intra-cerebroventricular da cafeina produz um aumento no número de impulsos gerados por neurônios da formação reticular mesencefálica, a tolerância se evidenciou a nivel neuronal, já que os ratos tratados cronicamente apresentaram um menor aumento do número de impulsos em relação ao grupo controle, quando submetidos às injeções intraventriculares. Esta ação sobre estes neurônios é tida como importante modo de ativação do SNC. Além disto, estes autores obtiveram um aumento de 12 e $27 \%$, respectivamente, no número de receptores da adenosina, para o tratamento crônico com as doses 5 e $10 \mathrm{mg} / \mathrm{Kg}$, sem, contudo, afetar a afinidade pelo receptor. Seus resultados comportamentais revelaram uma redução na atividade motora dos ratos tratados cronicamente com as doses de 5 ou $10 \mathrm{mg} / \mathrm{Kg}$, porém nenhuma diferença significativa foi constatada nos ratos tratados com a dose de $20 \mathrm{mg} / \mathrm{Kg}$.

Marangos et al (26) demonstraram que o tratamento crônico com cafeina, na dose de 40-60 mg/Kg/dia, por 16 ou 23 dias é capaz de aumentar significativamente o número de receptores da adenosina no cérebro de ratos, constituindo um fenômeno de "up regulation", o qual ocorre quando um determinado tipo de receptor é bloqueado por algum antagonista. Ainda, a captação de adenosina não sofreu alterações, o que sugere que o receptor de adenosina e o local de captação da mesma sejam entidades diferentes e com propriedades regulatórias diferentes.

São raros estudos detalhados a respeito do desenvolvimento de tolerância aos efeitos estimulatórios da cafeina sobre atividade motora. Holtzmann et al.(22) investigaram o desenvolvimento de tolerância em ratos através da administração diária de cafeina diluída em água, ofertada por 10 minutos, quatro vezes ao dia, por um longo período de 15 semenas. Avaliando unicamente a estimulação da atividade motora, constataram que, após 8 a 10 semanas, com uma dose diária média total de $160 \mathrm{mg} / \mathrm{Kg}$, não houve diferença significativa na ambulação destes ratos, quando submetidos a doses entre 0 e $100 \mathrm{mg} / \mathrm{Kg}$ por gavagem. Os seus controles, entretanto, apresentaram um pico de ambulação máxima com a dose de $25 \mathrm{mg} / \mathrm{Kg}$. Por outro lado, os ratos tratados cronicamente com cafeina foram estimulados de maneira praticamente idêncica aos não tratados, quando submetidos a doses de d-anfetamina, com aumentos proporcionais à dose (de $0 \mathrm{a}$ $6,25 \mathrm{mg} / \mathrm{Kg}$ ), o que sugere uma possivel especificidade farmacológica da tolerância à cafeina. Ainda, após a suspensão do tratamento crônico, houve uma diminuição na ambulação por 4 dias, produzindo-se um efeito consistente com um fenômeno da abstinência da droga; no seu quinto dia após a suspensão da droga, o nivel de atividade motora era igual àquele anterior ao tratamento. Duas a três semanas após a retirada, a sensibilidade ao efeito estimulatório da cafeína estava completamente restabelecida. Dando continuidade a este trabalho, Finn et al.(14) fizeram um estudo detalhado sobre o desenvolvimento e regressão da tolerância à cafeína com ratos que ingeriram a 
droga diluida em água, o que proporcionou uma dose diária de cerca de 19,36 ou $67 \mathrm{mg} / \mathrm{Kg}$. Os ratos foram submetidos a duas semanas de tratamento crônico, periodo em que a atividade motora foi avaliada. A curva dose-efeito foi determinada no final da segunda semana de tratamento, tendo sido demonstrado um pico de atividade motora com a dose de $30 \mathrm{mg} / \mathrm{Kg}$ para o grupo controle, bem como um desvio da curva para baixo (não para a direita) como efeito do tratamento. Isto significa que, mesmo com doses progressivamente maiores, não ocorreu aumento da atividade motora, exceto para o grupo submetido à menor dose ( $19 \mathrm{mg} / \mathrm{Kg})$, no qual percebeu-se um pequeno estímulo quando submetido a doses pequenas da droga. Utilizando então a dose de $30 \mathrm{mg} / \mathrm{kg}$ (por gavagem) para testar os ratos submetidos ao tratamento crônico com a dose de $36 \mathrm{mg} / \mathrm{Kg}$, verificaram que a tolerância se evidenciou já no primeiro dia deste tratamento, sem aumentar seu grau significativamente nos dias subseqüentes do mesmo. Após três dias de retirada da droga, a resposta a uma dose de $30 \mathrm{mg} / \mathrm{Kg}$ retornou praticamente aos niveis de antes do tratamento, revelando uma reversão da tolerãncia. Ao se avaliar a atividade motora espontânea (sem qualquer fator estimulante) após a retirada da droga, apenas os ratos submetidos à maior dose (67 mg/Kg) apresentaram um decréscimo significativo na ambulação, simulando uma sindrome de abstinência, $o$ que persistiu somente até o terceiro dia de retirada da droga. Com apenas um dia de tratamento ficou evidente a tolerância. As curvas dose-efeito foram redeterminadas duas semanas após a suspensão do tratamento e todos os ratos responderam de modo semelhante entre si e em relação a antes do tratamento, revelando um restabelecimento total da resposta estimulatória à droga.

Watanabe et al (31) testaram outra metilxantina, tendo conseguido demonstrar o desenvolvimento de tolerância após tratamento com teofilina $(25 \mathrm{mg} / \mathrm{Kg})$, via intra-peritonial, evidente desde o segundo dia de tratamento; no entanto esta tolerância somente se verificou em relação ao estimulo de rotação contra-lateral à lesão unilateral de neurônios dopaminérgicos nigroestriatais induzida por injeção estereotáxica de 6-OHDA (6-hidroxidopamina) no estriado (este comportamento de rotação parece estar mais relacionado com uma ação agonista direta das metilxantinas sobre os receptores dopaminérgicos). Por outro lado, estes autores não encontraram resultados que comprovassem o desenvolvimento de tolerância em relação ao estimulo da atividade motora com a mesma dose diária de teofilina, até o terceiro dia de tratamento com ratos não lesionados. Os resultados de Watanabe et al. (31) contrastam com os dados obtidos por outros pesquisadores no tocante à estimulação da atividade motora $(8,22,14)$

Considerando estas controvérsias e o pequeno número de estudos a respeito do desenvolvimento de tolerância ao efeito estimulatório da cafeina sobre atividade motora, decidiu-se avaliar, em laboratório, o desenvolvimento de tolerância à cafeina, valendo-se da atividade motora 
de ratos expostos a um ambiente novo por 10 minutos. Estes testes foram feitos após a primeira e a última injeção, em uma série de 14 injeções, sendo duas delas a cada dia, com $40 \mathrm{mg} / \mathrm{Kg}$ de cafeína, via intra-peritonial. Os ratos foram submetidos aos testes 30 minutos após as injeções. Os resultados, mostrados na tabela 1 , revelam que não houve diferença significativa na atividade motora entre a primeira e a última injeção, isto é, os ratos responderam à cafeína com um aumento da atividade motora mesmo após uma exposição crônica à droga, o que revela o não desenvolvimento de tolerância nas condições deste experimento. Os nossos resultados estão de acordo com os dados publicados por Watanabe et al (31), mas diferem daqueles publicados por Chou et al (8), Holtzman e colaboradores $(22,14)$.

Carney (2) utilizou um comportamento de resposta operante para demonstrar que a tolerância à cafeina se desenvolve em 7 dias com a administração de $32 \mathrm{mg} / \mathrm{Kg}$ via intraperitonial; os efeitos iniciais, diminuindo a resposta à droga, não foram mais evidenciados a partir do sétimo dia, retornando a resposta destes ratos ao nivel daquela do grupo controle. Houve um deslocamento para a direita de 6 vezes na curva dose-efeito, para a cafeina, a qual foi determinada no momento em que surgiu evidente tolerância. Utilizando um esquema comportamental similar ao descrito acima (2), Wayner et al.(33) constataram o desenvolvimento de tolerância após a primeira dose de cafeína em relação ao número de lambidas, o mesmo ocorrendo após o quinto dia, em relação ao número de vezes que a barra era pressionada. Estes dois trabalhos demonstraram que a tolerância à cafeina pode se desenvolver para uma situação bastante distinta da atividade motora espontânea e, além disto, Wayner et al.(33) demonstraram que a velocidade de desenvolvimento da tolerância à cafeina pode ser diferente para dois tipos de comportamentos em uma dada situação. As diferenças entre os resultados encontrados acima podem ser, em grande parte, devidas às diferenças entre os critérios metodológicos (incluindo tipo de comportamento avaliado, tempo das sessões comportamentais, habituação prévia ou não à situação de teste) utilizados na avaliação dos efeitos da droga, bem como do desenvolvimento de tolerância. Também pode ter contribuido para estes resultados contraditórios o fato de o tempo decorrido entre a exposição à droga e a avaliação dos seus efeitos não ter sido uniforme, nem a via de administração ter sido sempre a mesma. O sistema neuronal envolvido nas diferentes modalidades comportamentais não é sempre o mesmo, podendo haver diferentes ações da cafeina sobre cada um deles (1)

São raros os estudos feitos com humanos, muito embora a cafeina seja uma droga de amplo uso no mundo ocidental. Em um estudo com humanos, Cherek et al (6) mostraram que administração de café a consumidores habituais produziu uma inibição no comportamento agressivo destes individuos, ainda que houvesse um efeito estimulante do comportamento, avaliado pelo 
número de vezes que o individuo pressionava botões, resultando-lhe numa recompensa monetária. As doses utilizadas foram de 20, 140 e $260 \mathrm{mg}$ de cafeina, via oral. Nenhum dos indivíduos relatou irritabilidade, nervosismo ou tremores após a ingestão da droga. Os autores atribuem tais resultados ao fato de que todos os participantes eram usuários habituais da droga, portanto deveriam ser tolerantes a muitos dos seus efeitos. A metade deles ingeria diariamente mais de $200 \mathrm{mg}$ de cafeina, a outra metade ingeria menos de $100 \mathrm{mg}$. Esta diferença parece ter influenciado apenas a diminuição do comportamento agressivo, sendo que os maiores consumidores apresentaram uma redução de $58 \%$ na resposta agressiva, ao passo que os menores consumidores apresentaram uma redução de apenas $35 \%$ nesta resposta.

Goldstein et al.(17) avaliaram os efeitos comportamentais de doses de 150 e $300 \mathrm{mg}$ de cafeina em usuários crônicos e em não usuários. Constataram que os usuários crônicos necessitavam de cafeina para atingir um estado de alerta e prontidão suficiente para desempenharem suas atividades rotineiras. Caso a mesma não the fosse administrada, passavam a apresentar sintomas disfóricos, característicos de uma síndrome de abstinência à droga, dramaticamente revertidos pela administração da mesma. O intervalo de tempo necessário para que isto acontecesse (12 al6 h) era consistente com a meia-vida da cafeina em humanos ( $3.5 \mathrm{~h})$. Referem também que o grupo dos usuários foi muito mais intensamente afetado por efeitos agradáveis do que os não usuários. Efeitos estimulantes desagradáveis foram notados apenas pelos não usuários.

Jé foi demonstrada tolerância inequivoca adquirida à cafeina em relação a dois efeitos: diurese e secreção da glândula parótida $(12,35)$. O mesmo não aconteceu nitidamente com relação aos efeitos sobre o SNC, embora a mesma possa produzir distúrbios do sono mais intensos em não usuários, do que em usuários crônicos $(16,18,11)$

Os efeitos cardiovasculares já foram também estudados exaustivamente, porém resultados amplamente variáveis têm sido encontrados. Colton et al (11) administraram doses de $150 \mathrm{mg}$ de cafeina a usuários e não usuários, comparativamente, tendo encontrado respostas bradicárdicas mais frequentemente em não usuários crônicos expostos à dose referida ( $41 \%$ contra $23 \%$ ). Respostas taquicárdicas foram raramente encontradas em ambos os grupos, sem diferença de frequência entre eles. Dentre outros efeitos cardiovasculares atribuidos à cafeina, temos: pequenas elevações na pressão arterial sistólica e distólica, aumento do débito cardiaco, aumento ou diminuição na diferença arteriovenosa de oxigênio, aumento do consumo total de oxigênio, queda da resistência vascular periférica e várias alterações regionais de fluxo sangüineo. A bradicardia encontrada parece ser reflexa, por aumento do tônus vagal em resposta à leve hipertensão.Parece não haver diferenças farmacocinéticas entre usuários e não usuários, pois os niveis séricos não 
foram significativamente diferentes 1,2 e 3 horas após a ingestão oral de $300 \mathrm{mg}$, para ambos os grupos (18).

\section{INTERAÇÃO ENTRE AS METILXANTINAS E SISTEMA DOPAMINÉRGICO: POSSÍVEIS IMPLICAÇÕES CLÍNICAS}

Os estudos sobre as interações entre o sistema dapaminérgico e as metilxantinas é de grande importância, uma vez que tem sido sugerido que o efeito terapêutico de neurolépticos poderia ser prejudicado por estas substâncias de grande uso popular (3). Todavia deve ser ressaltado que são escassas as evidências experimentais que sustentam esta suposição.

Apesar do mimetismo exercido pelas metilxantinas, ao nivel comportamental, em relação aos agonistas dopaminérgicos diretos, Watanabe et al (32) demonstraram que a cafeina desloca muito pouco a espiperona tritiada de receptores dopaminérgicos (D2), indicando que esta tem pouca afinidade por receptores dopaminérgicos do tipo D2. Sabe-se, porém, que a cafeina tem efeito semelhante aos agonistas dopaminérgicos diretos, pois tem a capacidade de produzir rotação contra-lateral em ratos com lesões unilaterais dos neurônios do feixe nigro-estriatal, comportamento este associado a um estímulo pós sináptico dopaminérgico direto. Estas lesões unilaterais podem ser induzidas através de injeções estereotáxicas de 6-OHDA (6-hidroxidopamina) no estriado; uma ação agonista dopaminérgica direta se traduz por rotações contra-laterais ao lado lesado, realizadas pelo animal, o que pode ser inibido por antagonistas dopaminérgicos (3). Existe ainda a possibilidade de que a cafeina possa exercer seus efeitos comportamentais através de uma ação agonista direta em receptores dopaminérgicos D1, o que ainda não foi investigado, podendo talvez a cafeina deslocar ligantes D1, tal como o fazem os agonistas dopaminérgicos D1 $(30,21,23,28$, 9). Talvez um metabólito da cafeina possa estar exercendo este efeito agonista dopaminérgico. Já uma ação agonista indireta causaria rotação ipsilateral à lesão (3)

Os agonistas dopaminérgicos atuam em receptores pré-sinápticos (receptores D2) causando inibição da enzima tirosina-hidroxilase, acabando por diminuir a concentração de LDOPA, um produto de via biossintética da qual esta enzima faz parte (32). Com exposição à afeina, não se verifica tal ação, novamente sugerindo que esta não exerça agonismo direto em receptor dopaminérgico (D2). Por outro lado, a cafeína parece inibir o metabolismo da dopamina no sistema mesolimbico e nigro-estrial de modo muito semelhante a outros agonistas dopaminérgicos. É provável que o mecanismo de ação desta droga seja através de um agonismo indireto de receptores dopaminérgicos (32). 
Sabe-se que as metilxantinas são capazes de reverter o efeito cataleptogênico induzido por antagonistas dopaminérgicos, comumente agentes neurolépticos (3). Investigamos se o tratamento crônico com cafeína, acima descrito, poderia afetar a capacidade da mesma de reverter a catalepsia induzida por clorpromazina, numa tentativa de verificar se a tolerância se manifestaria em relação a esta capacidade. Os resultados obtidos revelaram que esta capacidade não se alterou após o tratamento crônico, o que está em concordância com os resultados obtidos no primeiro experimento realizado em nosso laboratório, acima descrito.

\section{CONCLUSÕES}

Embora alguns estudos já tenham sido realizados, a questão do possivel desenvolvimento da tolerância à cafeína ainda persiste sem uma conclusão definitiva. Talvez se pudesse chegar a uma idéia final realizando estudos mais detalhados com animais experimentais, englobando diferentes modalidades comportamentais, mas mesmo assim persistiria a dificuldade de se extrapolar conclusões para humanos, com objetivos clinicos. Parece útil que se faça um estudo clínico, utilizando diretamente humanos, com o objetivo de esclarecer as possiveis interações das metilxantinas com os neurolépticos na prática psiquiátrica

\section{TABELA 1}

Efeito da cafeína na atividade motora de ratos adultos

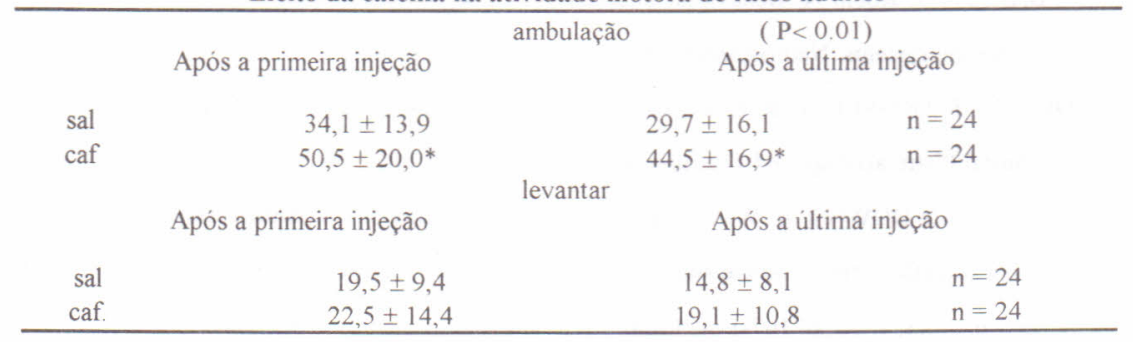

Os dados são apresentados como média desvio padrão. * Indica diferença significativa em relação ao grupo salina para $\mathrm{P}<0.01$

\section{BIBLIOGRAFIA CITADA}

1. BRADFORD, H. F. (1984). Neurochemicalbiology, Pergamon Press, New York. 
2. CARNEY, John M. Effects of caffeine, theophylline and theobromine on scheduled controled responding in rats. British Journal of Pharmacology, v. 75, p. 451-454, 1982.

3. CASAS, Miguel, FERRE, Sergi, GUIX, Teresa e JANE, Francesc. Teophylline reverses haloperidol-induced catalepsy in the rat. Biological Psychiatry, v. 24, p. 642-648, 1988.

4. CHAIT, L. D. e GRIFFITHS, R. R. Effects of Caffeine on Cigarrete Smoking and Subjective Response. Clinical Pharmacology and Therapeutics, v. 34, p. 612-622, 1983.

5. CHARNEY, D. S. ; GALlOWAY, M. P. HENINGER, G. R. The Effects of Caffeine on Plasma MHPG, Subjective Anxiety, Autonomic Symptoms and Blood Pressure in Healthy Humans. Life Sciences, v. 35, p. 135-144, 1984

6. CHEREK, D. R.; STEINBERG, J. L. e BRAUCHI J. T. Regular or decaffeinated coffee and subsequent human aggressive behavior. Psychiatry Research, v. 11, p.251-258, 1983

7. CHEUNG, W. Y. Properties of cyclic-3,5 nucleotide phosphodiesterase from rat brain. Biochemistry, v. 6, p. 1079-1087, 1967

8. CHOU, Doroty T.; KHAN, Sukur; FORDE, Jesse e HIRSH, Kenneth, R. Caffeine tolerance: behavioral, elecrophysiological and neurochemical evidence. Life Sciences, v.36, p.23472358,1985

9. CHRISTENSEN, A. V.; ARNT, J.; HYTTEL, J.; LARSEN, J. e SVENDSEN, 0. Pharmacological Effects of a Specific Dopamine D1 Antagonist SCH 23390 in Comparison with neuroleptics. Life Sciences, v. 34, p. 1529-1540, 1984.

10.COFFIN, Vicki L.; TAYLOR, Jeffrey A; PHILlIS, John W.; ALTMAN, Harvey J. e BARRACO, Robin A. Behavioral interaction of adenosine and methylxanthines on central purinergic systems. Neuroscience Letters, v. 47, p. 91-98, 1984

11.COLTON, T. GOSSELIN, R. E. e SMITH, R. P. The tolerance of coffee drinkers to caffeine. Clinical Pharmacology and Therapeutics, V. 9, p. 31-39, 1967

12.EDDY, N. B. e DOWNS, A. W. Tolerance and cross-tolerance in the human subject to diuretic effect of caffein, theobromine and Theophylline. Journal of Pharmacological \& Experimental Therapeutics, v. 33, p. 167-174, 1928.

13.EVANS, S. M. e GRIFFITS, R. R. Dose-related caffeine discrimination in normal volunteers individual differences in subjective effects and self-reported cues. Behavioral Pharmacology, v. 2 , p. $345-356,1991$.

14.FINN, Ira B. e HOLTZMAN, Stephen G. Tolerance to caffeine-induced stimulation of locomotor activity in rats. The Journal of Pharmacology and Experimental Therapeutics, v. 238 , p. $542-546,1986$ 
15.GOODMAN, L. S. e GILMAN, A. The Pharmacological Basis of Therapeutics. Sétima edição, 1985.

16.GOLDSTEIN, A. Wakefulness caused by caffeine. Arch. f. exper. Path. u. Pharmakol., v.248, p. 269-278, 1964.

17.GOLDSTEIN, A.; KAISER, S. and WHITBY, O. Psychotropic effects of caffeine in man. IV Quantitative and qualitative differences associated with habituation to coffee. Clinical Pharmacology and Therapeutics, v. 10, p. 489-497, 1969.

18.GOLDSTEIN, A.; WARREN, R. and KAISER, S. Psychotropic effects off caffein in man. I. Individual differences in sensitivity to caffein-induced wakefulness. Journal of Pharmacology \& Experimental Therapeutics, v. 149, p. 156-159, 1965.

19.GRIFFITHS, R. R.; EVANS, S. M.; HEISHMAN, S, J.; PRESTON, K. L.; SANNERUD, C. A.; WOLF; B. e WOODSON, P. P. Low Dose Caffeine Discrimination in Humans. Journal of Pharmacology and Experimental Therapeutics, v. 252, p. 970-978, 1990.

20.HENRY, J. P. e STEPHENS, P. M. Caffeine as an Intensifier of Stress-Induced Hormonal and Pathophysiologic Changes in Mice. Pharmacology Biochemistry \& Behavior, v. 13, p. 719727, 1980.

21.HESS, E. J. e CRESSE, I. Biochemical and Behavioral Studies of D1 Dopamine Receptors Utilizing SCH 23390. Advances in Experimental Medical Biology, v. 204, p. 29-52, 1986.

22.HOLTZMAN, Stephen G. Complete, reversible, drug-specific tolerance to stimulation of locomotor activity by caffeine. Life Sciences, v. 33, p. 779-787, 1983.

23.HYTTEL, J. e ARNT, J. Characterization of Dopamine D1 and D2 Receptors. Advances in Experimental Medical Biology, v. 204, p. 15-28, 1986.

24.KATIMS, Jefferson J.; ANNAU, Zoltan e SNYDER, Solomon H. Interactions in the Behavioral Effects of Methylxantines and Adenosine Derivatives. The Journal of Pharmacology and Experimental Therapeutics, v. 227, p. 167-173, 1983

25.LOKE, Wing Hong. Effects of caffeine on mood and memory. Physiology \& Behavior, v. 44, p.367-372, 1988.

26.MARANGOS, Paul, J.; BOULENGER, Jean Philippe e PATEL, Jitendra. Effects of chronic caffeine on brain adenosine receptors: regional and ontogenetics studies. Life Sciences, v. 34 , p. $899-907,1984$

27. OliVeIRA, E. M.; RUBIN, M. A.; BELLOI, C. R. B.; BELLOI, M. H. B. e ROCHA, J. B. T. Effect of caffeine administration on latent learning ability of male rats in a simple maze task. Brazilian Journal of Medical and Biological Research, v.23, p. 975-980, 1990. 
28.SIBLEY, D, R. e MONSMA, F. J. Molecular Biology of Dopamine Receptors. Tips Reviews, v.13, p. 61-69, 1992.

29.SNYDER, Solomon H.; KATIMS, Jefferson J.; ANNAU, Zoltan; BRUNS, Robert F. e DALY, John W. Adenosine receptors and behavioral actions of methylxantines. Proceedings of The National Academy of Sciences of USA, v.78, p. 3260-3264, 1981.

30.STOOF, J. C. e KEBABIAN, J. W. Two Dopamine Receptors: Biochemistry, Phisiology and Pharmacology. Life Sciences, v.35, p. 2281-2296, 1984.

31.WATANABE, Hiroshi; IKEDA, Momiko e WATANABE, Kazuo. Development of tolerance to dopaminergic stimulating effect of theophylline in mice with unilateral striatal 6hydroxidopamine lesions. European Journal of Pharmacology, v. 79, p. 125-128, 1982.

32.WATANABE, H. e URAMOTO, H. Caffeine mimics dopamine receptor agonists without stimulation of dopamine receptors. Neuropharmacology, v. 25, p. 577-581, 1986.

33.WAYNER, M. J.; JOLICOEUR, F. B.; RONDEAU, D. B. e BARONE, F. C. Effects of acute and chronic administration of caffeine on schedule dependent and schedule induced behavior. Pharmacology Biochemistry \& Behavior, v. 5, p. 343-348, 1976.

34.WHITE, B. C.; SIMPSON, C. C. e ADAMS, J. E. Monoamine synthesis and caffeine-induced locomotor activity. Neuropharmacology, v. 17, p. 511-513, 1978.

35.WINSOR, A. L. e STRONGIN, E. I. A study of the development of tolerance for caffeinated beverages. Journal of Experimental Psychology, v. 16, p. 725-744, 1933. 